\section{The top 10 research priorities in cystic fibrosis developed by a partnership between people with CF and healthcare providers}

\section{ABSTRACT \\ There remain many treatment uncertainties in cystic fibrosis (CF). With limited resources, research should focus on questions which are most important to the CF community. We conducted a James Lind Alliance Priority Setting Partnership in CF. Research questions were elicited and then prioritised in successive surveys. A workshop agreed the final top 10. Online methods avoided cross infection and widened participation. The elicitation survey had 482 respondents (1080 questions) and prioritisation survey 677 respondents. Participants were drawn equally from the patient and clinical communities globally. We have achieved a consensus on 10 research priorities which will be attractive to funders.}

\section{INTRODUCTION}

Therapies targeting the basic defect of cystic fibrosis (CF) are now available in the clinic, with more in development. ${ }^{1}$ However, conventional therapies for persistent airway infection and pancreatic malabsorption are still required and there remain many treatment uncertainties, which have yet to be clarified through well designed and adequately powered clinical trials. ${ }^{2}$

Both the Patient-Centered Outcomes Research Institute, in the USA, and the National Institute for Health Research (NIHR), in the UK, support patient involvement and 'co-production' of research. ${ }^{3}$ However, there has been no systematic and inclusive dialogue between clinicians, patients and parents about priorities for clinical research in CF. Face-to-face contact between patients is precluded due to risk of transmission of organisms such as Pseudomonas aeruginosa, providing a challenge to consultative exercises involving patients with $\mathrm{CF}^{4}$

The NIHR James Lind Alliance (JLA) supports Priority Setting Partnerships which bring patients, carers and clinicians together to prioritise research questions. Outcomes from JLA Priority Setting Partnerships have a track record of attracting significant research funding. ${ }^{5}$ We conducted a JLA Priority Setting Partnership in CF to identify the key treatment uncertainties for the CF community and produce the top 10 research questions for treatment and management of CF.

\section{METHODS}

Our Priority Setting Partnership took place in March 2016-January 2017. We published our protocol before commencing (http://eprints.nottingham.ac.uk/35223/). We followed JLA methodology, ${ }^{6}$ adapting the process using online methods to avoid risk of cross infection. Our steering group was selected to include lay members (two people with CF and two parents) and professionals from each discipline: two respiratory paediatricians, respiratory physician, physiotherapist, dietitian, nurse, pharmacist, clinical psychologist and social worker. We also included a specialist commissioner, UK Cystic Fibrosis Trust representative and four academics (systematic reviewer, qualitative researcher, project manager and academic clinical fellow).

From March to June 2016, we conducted the first of two online surveys (Survey

Monkey). The elicitation survey requested respondent demographics and asked a single question 'What question on Cystic Fibrosis would you like to see answered by research?' Respondents could submit up to five questions. The survey was advertised through professional groups, clinic posters and our bespoke Twitter account (@questionCF).

Two researchers (NR and SS) independently reviewed all questions submitted with adjudication by the steering group. Non-questions and questions unrelated to treatment were removed. We conducted a systematic review of evidence gaps in $\mathrm{CF}^{7}$ and excluded any questions already answered. Where several questions addressed the same issue, they were consolidated into a single 'standardised question'.

The steering group undertook a Delphi ${ }^{8}$ assessment of the standardised questions to produce a shortlist for the prioritisation
Table 1 Demographic characteristics of respondents to elicitation survey and prioritisation survey. Of the 513 responses to elicitation survey, 31 were from respondents who completed the survey more than once (482 individual respondents). Data are presented as number (\%) or median (range)

\begin{tabular}{|c|c|c|}
\hline Characteristic & $\begin{array}{l}\text { Elicitation survey } \\
(\mathrm{n}=482)\end{array}$ & $\begin{array}{l}\text { Prioritisation survey } \\
(\mathrm{n}=677)\end{array}$ \\
\hline Male & $111(23.0)$ & $153(22.6)$ \\
\hline Female & $315(65.4)$ & $454(67.1)$ \\
\hline Did not answer & $56(11.6)$ & $70(10.3)$ \\
\hline Median age (range) & $42(6-82)$ & $41(6-82)$ \\
\hline \multicolumn{3}{|l|}{ Category of respondent } \\
\hline Lay persons & $224(46.5)$ & $314(46.4)$ \\
\hline Person with cystic fibrosis & 95 (19.7) & $121(17.9)$ \\
\hline Parent of person with cystic fibrosis & $105(21.8)$ & $160(23.6)$ \\
\hline Family and friends & $24(5.0)$ & $33(4,9)$ \\
\hline Professionals & $211(43.8)$ & $303(44.8)$ \\
\hline Medical doctor & $61(12.7)$ & 85 (12.6) \\
\hline Nurse & $22(4.6)$ & $32(4.7)$ \\
\hline Physiotherapist & $49(10.2)$ & $65(9.6)$ \\
\hline Dietitian & $31(6.4)$ & $41(6.1)$ \\
\hline Pharmacist & $6(1.2)$ & $18(2.7)$ \\
\hline Social worker & $7(1.5)$ & $16(2.4)$ \\
\hline Non-clinical researcher & $10(2.1)$ & $7(1.0)$ \\
\hline Psychologist & $21(4.4)$ & $38(5.6)$ \\
\hline Other & $4(0.8)$ & $1(0.1)$ \\
\hline Did not answer & $47(9.8)$ & $60(8.9)$ \\
\hline \multicolumn{3}{|l|}{ Country } \\
\hline UK & $249(51.7)$ & $474(70.0)$ \\
\hline USA and Canada & $91(18.9)$ & $70(10.3)$ \\
\hline Rest of Europe & $45(9.3)$ & $42(6.2)$ \\
\hline Australia and New Zealand & $35(7.3)$ & $22(3.2)$ \\
\hline Other & $5(1.0)$ & $5(0.7)$ \\
\hline Did not answer & $57(11.8)$ & $64(9.5)$ \\
\hline
\end{tabular}


survey. This allowed participants to rank their top 10 questions (SeptemberNovember 2016). The prioritisation survey was advertised through Twitter and by emailing participants who completed the elicitation survey.

The top 20 questions chosen through the prioritisation survey were then discussed at a workshop in January 2017. Lay and professional participants (recruited through the prioritisation survey), all with equal voice, led by three independent JLA facilitators, selected the final top 10 research priorities, through a process of small group discussion and plenary voting. Patient representatives joined remotely from home and hospital using video conferencing.

\section{RESULTS}

We had 513 replies to the elicitation survey, of which 31 completed the survey more than once, leaving 482 respondents who submitted 1080 questions. Table 1 shows the demographics of elicitation survey respondents. There were $224(46.5 \%)$ lay respondents, 211 (43.8\%) professionals and $47(9.8 \%)$ were unknown. Just over half were from the UK, with submissions from 23 countries in total.

Figure 1A describes how the questions were sorted and refined. There were 704 treatment and management questions which were combined into 127 standardised questions. Following the Delphi process, 71 questions were taken forward for prioritisation. The prioritisation survey was completed by 677 respondents (see table 1 for demographics). The final top 10 questions are shown in figure $1 \mathrm{~B}$.

\section{DISCUSSION}

We have undertaken the first JLA Priority Setting Partnership in CF, with equal numbers of participants from the patient and clinical communities. We have produced a top 10 list of clinical research questions in $\mathrm{CF}$, which will be attractive to both researchers and funders.
There has been little previous work of this kind. The Italian Patient-Centered Outcomes CF Research Group canvassed opinion from 12 clinical researchers and eight 'expert stakeholders'. ${ }^{9}$ This exercise prioritised five topics: transplantation, Cystic Fibrosis Transmembrane Conductance Regulator (CFTR) modulators, $P$. aeruginosa, Burkholderia cepacia and allergic bronchopulmonary aspergillosis. The management of infection in CF also featured in our top 10-non-tuberculous mycobacteria $(\mathrm{Q} 3)$ and $P$. aeruginosa (Q10). Infection with $P$. aeruginosa has previously been shown to be a great concern to parents and patients with CF. ${ }^{10}$ Surprisingly, questions on CFTR modulators were absent from our top 10. Respondents might assume this research will progress whether or not prioritised.

The strength of our study is our global reach and the large numbers of respondents, representing the whole CF community. Online surveys give less granular data than approaches such as focus groups. An
A

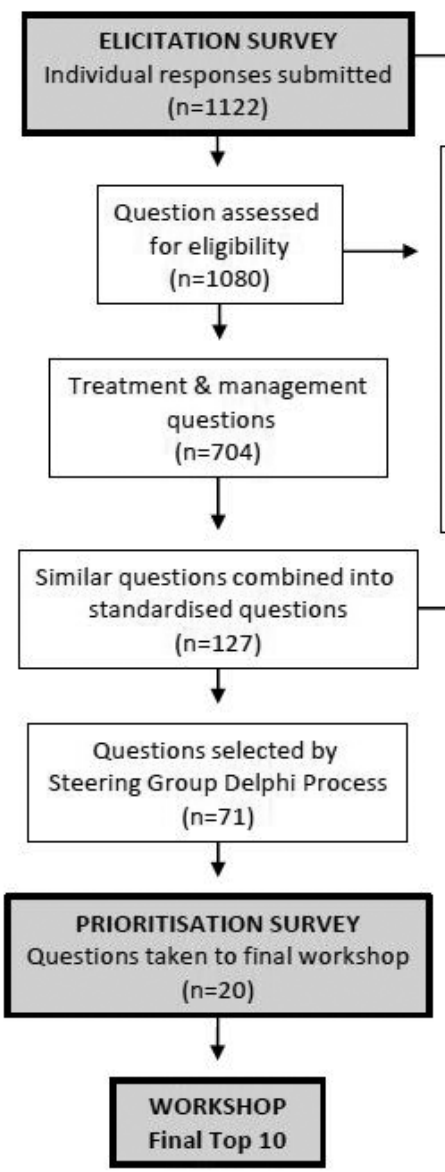

B

1. What are the effective ways of simplifying the treatment burden of people with Cystic Fibrosis?

2. How can we relieve gastro-intestinal (GI) symptoms, such as stomach pain, bloating and nausea in people with Cystic Fibrosis?

3. What is the best treatment for non-tuberculous mycobacteria (NTM) in people with Cystic Fibrosis (including when to start and what medication)?

4. Which therapies are effective in delaying or preventing progression of lung disease in early life in people with Cystic Fibrosis?

5. Is there a way of preventing CF related diabetes (CFRD) in people with Cystic Fibrosis?

6. What effective ways of motivation, support and technologies help people with Cystic Fibrosis improve and sustain adherence to treatment?

7. Can exercise replace chest physiotherapy for people with Cystic Fibrosis?

8. Which antibiotic combinations and dosing plans should be used for Cystic Fibrosis exacerbations and should antibiotic combinations be rotated?

9. Is there a way of reducing the negative effects of antibiotics, for example resistance risk and adverse symptoms in people with Cystic Fibrosis?

10. What is the best way of eradicating Pseudomonas aeruginosa in people with Cystic Fibrosis?

Figure 1 (A) James Lind Alliance Priority Setting Partnership in CF. Flow chart of submitted questions, showing the process for selecting the final top 20. (B) The top 10 questions for clinical research in cystic fibrosis. 
alternative approach to ours-focus groups, using video conferencing-would also avoid cross infection. Key aspects of our robust methodology were a representative steering committee, a systematic review of research gaps and having two researchers independently processing questions. Our experience of using online surveys, promotion through social media and video conferencing may be useful to other patient engagement exercises in respiratory medicine and beyond where face-to-face meetings are restricted by infection control, geography or frailty of participants. The US CF Foundation 'Insight CF' engagement programme has adopted a similar approach to registry-based research.

The items on the top 10 list are not prescriptive, rather they allow research groups to formulate a testable hypothesis with the appropriate study design. We are in discussion with the NIHR Evaluation, Trials and Studies Coordinating Centre about topics from our top 10, suitable for NIHR-commissioned research. We hope that this exercise will invigorate research in areas of shared importance to both the patient and the clinical community and demonstrate the value of involving the whole CF community in all steps of the research pathway.

\section{Nicola J Rowbotham, ${ }^{1}$ Sherie Smith, ${ }^{1}$ Paul A Leighton, ${ }^{2}$ Oli C Rayner, ${ }^{3}$ Katie Gathercole, ${ }^{3,4}$ Zoe C Elliott, $^{5}$ Edward F Nash, ${ }^{6}$ Tracey Daniels, ${ }^{7}$ Alistair J A Duff, ${ }^{8}$ Sarah Collins, ${ }^{9}$ Suja Chandran, ${ }^{10}$ Ursula Peaple, ${ }^{11}$ Matthew N Hurley, ${ }^{1}$ Keith Brownlee, ${ }^{12}$ Alan R Smyth ${ }^{1}$}

${ }^{1}$ Evidence Based Child Health Group, University of Nottingham, Nottingham, UK

${ }^{2}$ School of Medicine, NIHR Research Design Service for the East Midlands, University of Nottingham, Nottingham, UK

${ }^{3}$ Person with Cystic Fibrosis, Plymouth, UK

${ }^{4}$ School of Education, University of Leeds, Leeds, UK

${ }^{5}$ Parent of Children with CF, Nottingham, UK

${ }^{6}$ West Midlands Adult CF Centre, Heart of England NHS Foundation Trust, Birmingham, UK

${ }^{7}$ Department of Physiotherapy, York Hull Adult CF Unit, York Teaching Hospital NHS Foundation Trust, York, UK ${ }^{8}$ Department of Clinical Psychology, Leeds Teaching Hospital NHS Trust, Leeds, UK

${ }^{9}$ Department of CF, Royal Brompton and Harefield NHS Trust, London, UK

${ }^{10}$ Regional Paediatric CF Centre, Kings College Hospital, London, UK

${ }^{11}$ National Team Specialised Commissioning, NHS England, London, UK

${ }^{12}$ Cystic Fibrosis Trust, London, UK

Correspondence to Professor Alan R Smyth, Evidence Based Child Health Group, Division of Child Health, Obstetrics \& Gynaecology, Queens Medical Centre, Nottingham NG7 2UH, UK; alan.smyth@nottingham. ac.uk

Acknowledgements The JLA Priority Setting Partnership in CF has only been possible due to the enthusiastic contributions from people with CF, their family and friends, healthcare professionals and other key members of the CF community. Organisations that contributed towards this process include the CF Trust CF Aware, CF Unite, and the Cochrane Cystic Fibrosis and Genetic Disorders Group.

Contributors All authors contributed to the design, recruitment, data analysis and in the preparation of the manuscript.

Funding The project was funded by a CF Trust Venture and Innovation Award (VIA025) and grants from the University of Nottingham and Nottingham Hospitals Charity. NJR is an NIHR Academic Clinical Fellow.

Competing interests Outside the submitted work: NJR reports non-financial support from Teva. TD reports personal fees from Raptor pharmaceuticals and nonfinancial support from Teva. UP reports personal fees from Dewi WHughes Ltd NHS Mentoring. ARS reports personal fees from Vertex, PTC, Roche and Gilead. In addition, ARS has a patent Application No. 14737297.3 (in Europe) Biomarkers for Pseudomanas aeruginosa for The University of Nottingham pending and has taken part in clinical trials sponsored by Vertex, Raptor and Insmed. Other authors have no competing interest to decline.

Ethics approval The University of Nottingham Research Ethics Committee deemed this work not to require ethical approval.

Provenance and peer review Not commissioned; externally peer reviewed.

Data sharing statement We plan to make anonymised data available within one year of publishing this article via an online repository such as Dryad or upon reasonable application.

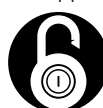

\section{OPEN ACCESS}

Open Access This is an Open Access article distributed in accordance with the Creative Commons Attribution Non Commercial (CC BY-NC 4.0) license, which permits others to distribute, remix, adapt, build upon this work non-commercially, and license their derivative works on different terms, provided the original work is properly cited and the use is noncommercial. See: http://creativecommons.org/licenses/ by-nc/4.0/

(C) Article author(s) (or their employer(s) unless otherwise stated in the text of the article) 2018. All rights reserved. No commercial use is permitted unless otherwise expressly granted.

\section{Check for updates}

To cite Rowbotham NJ, Smith S, Leighton PA, et al. Thorax 2018;73:388-390.

Received 3 May 2017

Revised 3 June 2017

Accepted 19 June 2017

Published Online First 4 August 2017

Thorax 2018;73:388-390.

doi:10.1136/thoraxjnl-2017-210473

\section{REFERENCES}

1 Mayer-Hamblett N, Boyle M, VanDevanter D. Advancing clinical development pathways for new CFTR modulators in cystic fibrosis. Thorax 2016;71:454-61.

2 Jahnke N, Remmington T, Smyth AR. Finding and filling the gaps in the evidence with high quality clinical trials - the experience of one Cochrane Review Group. J Evid Based Med 2013:6:229-31.

3 Rowbotham NJ, Smyth AR. The patient voice in research - supporting actor or starring role? I Cyst Fibros 2017:16:313-4.

4 Saiman L, Siegel JD, LiPuma JJ, et al. Infection prevention and control guideline for cystic fibrosis: 2013 update. Infect Control Hosp Epidemiol 2014;35(Suppl 1):S1-67.

5 Lloyd K, White J, Chalmers I. Schizophrenia: patients research priorities get funded. Nature 2012;487:432

6 Cowan K, Oliver S. The James Lind alliance guidebook (version 6). Southampton, UK: James Lind alliance, 2016.

7 Rowbotham NJ, Smith S, Robinson KA, et al. 233 gaps in the evidence for treatment decisions in cystic fibrosis: a systematic review. J Cyst Fibros 2016:15:S110.

8 Murphy MK, Black NA, Lamping DL, et al. Consensus development methods, and their use in clinical guideline development. Health Technol Assess 1998;2:1-88.

9 Cirilli N, Buzzetti R, Costa S, et al. 282 patient priorities for research in cystic fibrosis: the IPaCOR experience. $J$ Cyst Fibros 2014;13(Suppl 2):S120.

10 Palser SC, Rayner OC, Leighton PA, et al. Perception of first respiratory infection with Pseudomonas aeruginosa by people with cystic fibrosis and those close to them: an online qualitative study. BMJ Open 2016;6:e012303. 